\title{
Nanomodificated Surface CoCr Alloy for Corrosion Protection of MoM Prosthesis
}

\author{
Cristina Díaz ${ }^{1}$, Stephan Mändl2 ${ }^{2}$, Rosario Pereiro ${ }^{3}$, Beatriz Fernández ${ }^{3}$ \\ ${ }^{1}$ Surface Engineering Technological Center, Association of Navarra Industry, Pamplona, Spain \\ ${ }^{2}$ Leipzig Institute of Surface Modification, Leipzig, Germany \\ ${ }^{3}$ Department of Physical and Analytical Chemistry, Faculty of Chemistry, University of Oviedo, Oviedo, Spain \\ Email: cdiaz@ain.es
}

Received 24 February 2015; accepted 18 March 2015; published 24 March 2015

Copyright (C) 2015 by authors and Scientific Research Publishing Inc.

This work is licensed under the Creative Commons Attribution International License (CC BY). http://creativecommons.org/licenses/by/4.0/ (c) (†) Open Access

\begin{abstract}
Problems in metal-on-metal (MoM) hip replacement systems still persist due to high wear rates, low corrosion resistance and release of toxic ions and nanoparticles. As a consequence of these effects, failure, infections, loosening or bone resorption is the typical problems in the hip prosthesis. In order to reduce failure due to corrosion and/or releasing ions and particles, this study presents some works in a novel nanoscale surface modification of cobalt-chromium alloy (CoCr) for obtaining improved surface conditions in these alloys for these applications. Improving corrosion resistant of these alloys and achieving a low wear rate are possible to reduce the total released ions and particles released from the surface of this material. According to it, three different treatments using oxygen at temperatures of $300^{\circ} \mathrm{C}, 350^{\circ} \mathrm{C}$ and $400^{\circ} \mathrm{C}$ were carried out by plasma immersion ion implantation technique (PI3). X-ray diffraction (XRD) analysis shows an increase in the formation of chromium oxides in the outer surface of the CoCr alloy. It allows improving in corrosion resistant in $\mathrm{CoCr}$ alloys. Moreover, total quantity of released $\mathrm{Co}, \mathrm{Cr}$ and Mo ions have been reduced. Wear rate studies showed a very similar behaviour after the treatments in relation to untreated CoCr alloy and release rate from the treated surface of $\mathrm{CoCr}$ alloys was reduced in comparison with untreated CoCr alloy.
\end{abstract}

\section{Keywords}

Plasma Immersion Ion Implantation, THR, Nanoparticles, Ion Release

\section{Introduction}

Every year, about one million patients worldwide undergo total hip arthroplasty (THA) surgery. This is consid-

How to cite this paper: Díaz, C., Mändl, S., Pereiro, R. and Fernández, B. (2015) Nanomodificated Surface CoCr Alloy for Corrosion Protection of MoM Prosthesis. Journal of Biomaterials and Nanobiotechnology, 6, 91-99.

http://dx.doi.org/10.4236/jbnb.2015.62009 
ered a successful, safe and cost-effective medical intervention to restore functionality of the hip joint and to regain pain-free mobility in patients suffering from severe joint disease or trauma. The number of people undergoing primary a total hip arthroplasty (THA) and revision surgery is expected to increase further due to an ageing population, decreasing average age at the first operation and the limited life span of prostheses [1].

In most industrialised countries, THA has an incidence higher than 150 procedures per 100,000 habitants and year [2]. In general, about one million of hips are replaced by artificial prostheses around the world every year. Only in the United States, it is extrapolated that the increasing number of primary THA and revision procedures will increase the annual cost from 8.43 billion \$ in 2003 to 22.7 billion \$ in 2030 [3].

Wear is recognized as the most important limitation to long term stability of hip devices. THA has been reported to fail in younger patients with more active lifestyles [4]. Hip resurfacing (HR) is proposed as a boneconserving alternative to the conventional THA for young and active patients after optimal medical therapy fails [5].

Metals such as stainless steels (SS), titanium alloys (Ti) and CoCr alloys are required in orthopaedic applications because they exhibit elevated mechanical strength and fracture toughness. Recently, the metallic materials most used in MoM hip prosthesis are $\mathrm{Ti}$ and $\mathrm{CoCr}$ alloys [6]. Ti alloys are considered as one of the most biocompatible metals, and they present an excellent corrosion resistance but poor mechanical properties. On the other hand, $\mathrm{CoCr}$ alloys exhibit elevated mechanical properties and good corrosion resistance under friction condition [7], what apparently made it most suitable for MoM hip prosthesis with lower wear rates than titanium-ultrahigh molecular weight polyethylene (Ti-UHMWPE) wear couples [8].

One of the most advanced hip replacements is the Birmingham Hip Resurfacing system (BHR) in its type of a metal on metal (MoM) joint [9] [10]. However, recent information about the wear of certain metal-on-metal devices has raised concerns about their use. By 2010, reports in the orthopaedic literature have increasingly cited the problem of early failure of metal on metal prostheses in a small percentage of patients [11]. Failures may relate to release of minute metallic particles or metal ions from wear of the implants, causing pain and disability severe enough to require revision surgery in $1 \%-3 \%$ of patients [12].

However, common concerns with all MoM hip prostheses are related to the unclear role of long-term exposure to metal ions released into the human body. Wear and corrosion effects of MoM implants are still judged on the basis of metal-ion concentrations revealed in blood, serum or urine [13]. These ions act highly specific when inducing a tissue response. Over the time, the level of metal ions may become clinically significant, resulting in implant failure, osteolysis, and allergic reactions [5]. For cobalt ions $\left(\mathrm{Co}^{2+}\right)$, multiple pathways have been identified depending on the local concentration, including apoptosis, increased expression of the hypoxia-inducible factor-1(HIF-1 $\alpha$ ) for endothelial cells [14] and increased osteoclasts activity [15].

A multitude of biomedical processes are activates by nanoscopic wear particles. In the vicinity of protheses, stimulation of macrophages and lymphocytes to pro produce proinflammatory mediators is observed, leading to enhanced osteoclast formation, with increased osteolysis of bone material [16]-[18]. Additionally, the transformation of macrophages towards osteoclast-like cells which resorb bone was observed after phagocytosing wear particles [19]. Spreading across the whole body and accumulation in vital organs, as spleen, liver and lung has been reported with negative effects [20] [21]. Only a minor influence of the chemistry for nanoparticles is observed here as these processes have been reported for a multitude of different particles [22] [23]. Additional problems can arise from incomplete surface repassivation after tribological processes destroy an oxide passivation layer and exposes fresh material to corrosion leading to the creation of new, brittle oxide on the surface which is then leading to even more particles [7].

While downstream biochemical regulation to prevent such negative influences of wear particles have been reported recently [24], a more practical route involves advanced surface modification techniques to alleviate these problems. However, conformality, defect density and adhesion aspects have to be considered when choosing a suitable method for surface modification. Plasma immersion ion implantation technique (PI3) is one possibility where synergy effects from simultaneous improvements in topology, tribology and corrosion behaviour can be obtained for biomaterials [25]-[27]. The present study describes the surface modification of F-799 CoCr alloy using oxygen PI3. In this work, low ion energies and low temperatures $\left(300^{\circ} \mathrm{C}-400^{\circ} \mathrm{C}\right)$ were studied, to prevent changes in the microstructure of the bulk material while obtaining excellent corrosion resistance at the surface. Additionally, wear rate and released ions were studied in $\mathrm{CoCr}$ alloys after using the proposed surface treatment and these experimental results were compared to those obtained with $\mathrm{CoCr}$ alloys without treatment. The aim of this study is to establish treatment conditions to obtain the best protection properties on the surfaces 
of CoCr alloys in order to reduce the release of ions from its surface. The modified surface topography was of less importance as the articulating surfaces and not the surface for bone and tissue integrating were targeted in this experiment.

\section{Experimental}

A medical grade CoCrMo ASTM F-799 alloy was obtained as a commercial material. All the samples were mirror polished with a $1 \mu \mathrm{m}$ diamond suspension and cleaned in an acetone ultrasonic bath before making the different treatments. Oxygen PI3 experiments were carried out in a HV chambers at a base pressure lower than $10^{-4} \mathrm{~Pa}$ and a working pressure of $0.2 \mathrm{~Pa}$. The plasma for oxygen implantations was generated by an RF plasma source operating at $40.68 \mathrm{MHz}$. For these experiments, a voltage pulse of $10 \mathrm{kV}$ was used, with a total incident fluency of $6 \times 10^{18}$ oxygen atoms ${ }^{\cdot} \mathrm{cm}^{-2}$ during a processing time of $1 \mathrm{~h}$. at temperatures of $300^{\circ} \mathrm{C}, 350^{\circ} \mathrm{C}$ and $400^{\circ} \mathrm{C}$. The process temperature was determined with a pyrometer calibrated against a thermocouple above space of samples [28].

Quantitative depth-profiles of different elements were measured by glow discharge optical emission spectroscopy (GD-OES) using a JY GD Profiler HR (Jobin-Yvon Horiba, France) with RF source operating at 650 $\mathrm{Pa}$ and $40 \mathrm{~W}$. Corrections were applied to the optical signals in order to take into account the influence of the residual hydrogen signal. Our interest was to evaluate possible changes in depth profile analysis after corrosion tests. Then, it could be possible to estimate movements or displacements of $\mathrm{Co}, \mathrm{Cr}$ and $\mathrm{Mo}$ ions inside the material after the treatment.

Corrosion tests were conducted under ASTM G5-94 standard, at $37^{\circ} \mathrm{C} \pm 0.2^{\circ} \mathrm{C}$ using bovine serum (BSA), containing 20 - $23 \mathrm{~g} \cdot \mathrm{l}^{-1}$ of proteins. A conventional three-electrodes cell with a Pt wire as counter-electrode (CE), an $\mathrm{Ag} / \mathrm{AgCl}$ electrode as reference electrode (RE) and implanted sample as working electrode (WE) were prepared. Electrodes were connected to a Gamry Instrument set-up which was used to record polarisation curves. Samples were loaded into the electrochemical cell after being recovered with resin, except for an area of 0.125 $\mathrm{cm}^{2}$. After 20 minutes of immersion in BSA, open-circuit specimen potentials (OCP) were obtained. After that, samples were immersed and potential scan limited between $\pm 300 \mathrm{mV}$ was started. In all experiments, polarisation potential sweep rate was kept to $0.17 \mathrm{mV} \cdot \mathrm{s}^{-1}$.

Moreover, these surfaces were studied by tribocorrosion tests using serum bovine (BSA) controlled at $\mathrm{pH} 7.0$ and $37^{\circ} \mathrm{C} \pm 0.2^{\circ} \mathrm{C}$. Tribocorrosion tests were carried out by Microtest MT/30/NI equipment in ball-on-disk configuration. Treated samples were tested against a counterpart of F-799 $\mathrm{CoCr}$ alloy without any treatment. After tribocorrosion tests: a) for one hand, the volume loss in the wear track was measured by using an optical profilometer WYCO RST 500 and wear rates was calculated for each sample, and b) for another hand, rests of bovine serum using during the wear tests (BSA) were analyzed by inductively coupled plasma mass spectrometry (ICP-MS) using an equipment from Agilent $(7500 \mathrm{c})$ in order to determinate quantity of metal ions released during wear tests. Furthermore, an x-ray diffraction system (XRD) Siemens D-5000 (Cu K $\alpha(\lambda=0.1540 \mathrm{~nm}$ radiation) analysis using a grazing angle of $0.5^{\circ}$ were carried out to establish the oxides formed in the surfaces after each treatment.

\section{Results and Discussion}

\subsection{GD-OES Analysis}

Oxygen implantation into $\mathrm{CoCr}$ alloy has found to reduce $\mathrm{Co}$, $\mathrm{Cr}$ and Mo concentrations in the immediate surface. However, while $\mathrm{Cr}$ and Mo started around $5 \mathrm{~nm}$ increasing until the corresponding values of the reference samples were reached, the profiles of Co after treatment showed a reduction around 30\% - 50\% until about $5 \mathrm{~nm}$ and then around 15 - $30 \mathrm{~nm}$ this profiles increased until reference values (Figure 1 and Figure 2). These reductions were stronger at $300^{\circ} \mathrm{C}$ and $400^{\circ} \mathrm{C}$, where they reached $5 \%$ of Co until about $30 \mathrm{~nm}$ in depth (Figure 2). Hence, a strong oxygen induced surface segregation of the alloying elements was observed.

\subsection{Potentiodynamic Polarisation Curves}

Figure 3 represents polarisation curves of titanium-aluminium-vanadium (TiAlV) and CoCr alloy references. As can be seen, the current density (icorr) of TiAlV is around two orders of magnitude over the value of the corrosion current density (jcorr) of the reference sample of CoCr alloy. It means, TiAlV is better to corrosion behaviour 


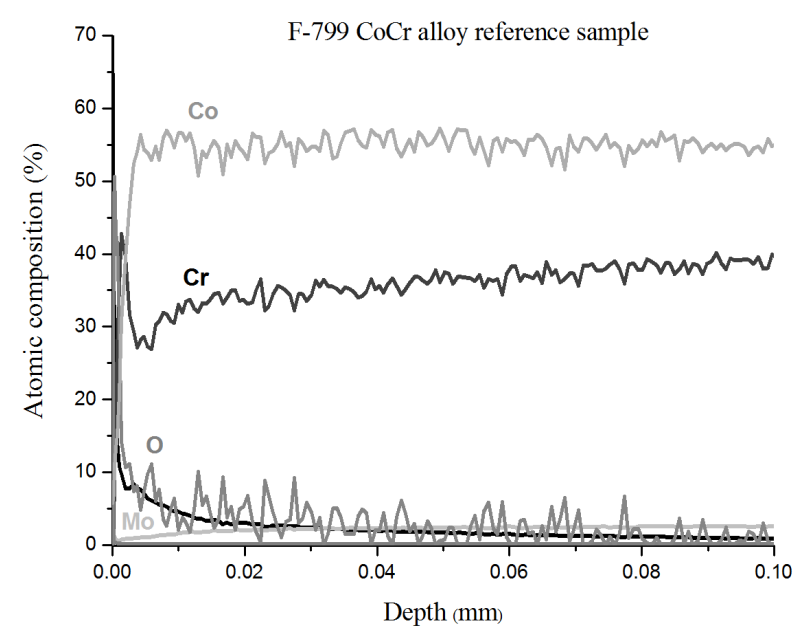

Figure 1. Depth profile analysis of a reference F-799 $\mathrm{CoCr}$ alloy obtained by GD-OES.

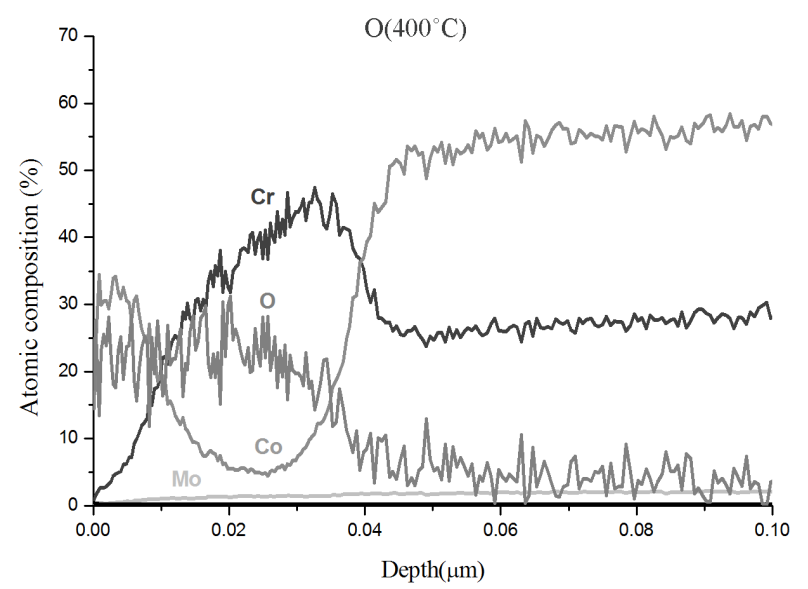

Figure 2. Changes of Co, Cr and Mo observed in the depth profile of an F-799 CoCr alloy after PI3 surface modification using oxygen in relation to untreated sample.

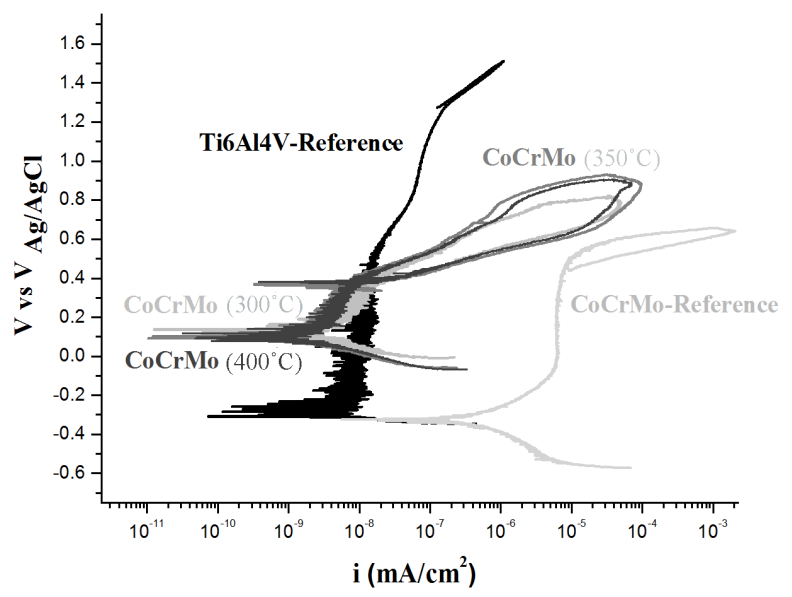

Figure 3. Polarization curves for TiAlV and CoCrMo reference samples and CoCrMo treated samples by oxygen plasma immersion ion implantation in BSA solution at $37.2^{\circ} \mathrm{C}$. 
in BSA than CoCr alloys. In order to reduce this difference in corrosion behaviour between both materials, some treatments were carried out over $\mathrm{CoCr}$ alloy. Figure 3 represents the improvement in resistant corrosion of treated CoCr alloy in relation to TiAlV without any treatment. All treated $\mathrm{CoCr}$ alloys showed similar behaviour to corrosion resistant. Now, the current density between both materials was very similar keeping near in the same order of magnitude. Also, the corrosion potential was slightly superior in treated CoCr. However, although $\mathrm{CoCr}$ alloys were improved in resistant corrosion, their polarisation curves presented lower capacity to passivation and recovered after the cycling of corrosion. So, it can be said that $\mathrm{CoCr}$ alloy treated by oxygen slightly could have a resistant corrosion excellent in BSA and similar to TiAlV in corrosion.

\subsection{Wear Tests}

The wear rate of treated CoCr was measured in relation to untreated CoCr (Table 1). The surface modification did not change the friction coefficient compared to untreated $\mathrm{CoCr}$ alloy. In contrast, the results revealed a wear rate of around $6-7 \times 10-14 \mathrm{~m}^{3} \cdot \mathrm{N}^{-1} \cdot \mathrm{m}^{-1}$ for all of samples. In this rate, $\mathrm{O}\left(400^{\circ} \mathrm{C}\right)$ treated sample showed the best improvement in wear test in $\mathrm{BSA}$ at $37^{\circ} \mathrm{C} \pm 0.2^{\circ} \mathrm{C}$, reducing the wear rate by around $15 \%$ in relation to untreated CoCr. Figure 4 shows a picture of the collected particles after wear tests of $\mathrm{O}\left(400^{\circ} \mathrm{C}\right)$ treated sample in BSA. The size of these particles was between $3.0-3.5 \mu \mathrm{m}$, the highest ones, and around $100-200 \mathrm{~nm}$ the smallest ones, approximately. Composition analysis of them by EDS showed some rests of oxygen, cobalt and chromium in their surface (Figure 4).

\subsection{Ion Release}

After wear tests the BSA was collected and analysed in two different procedures. On one hand, the collected BSA solution after wear tests was selected, including some particles. On the other hand, BSA solution was filtering out particles under $220 \mathrm{~nm}$ and such solution was also analysed by ICP-MS. The results showed a significant influence in the released ions concentration by particles in the solution after wear tests. Figure 5 represents total ion releasing (in $\mathrm{ng} \cdot \mathrm{g}^{-1}$, ppb) divided in $\mathrm{Co}$, Cr and Mo concentrations, just after wear tests. As can be seen, the total quantity of released ions from the treated samples was lower than from an untreated sample. Figure 5 shows that the highest reduction in treated samples was for Co ions in relation to untreated samples with more or less no change for the already low release rates of $\mathrm{Cr}$ and Mo ions.
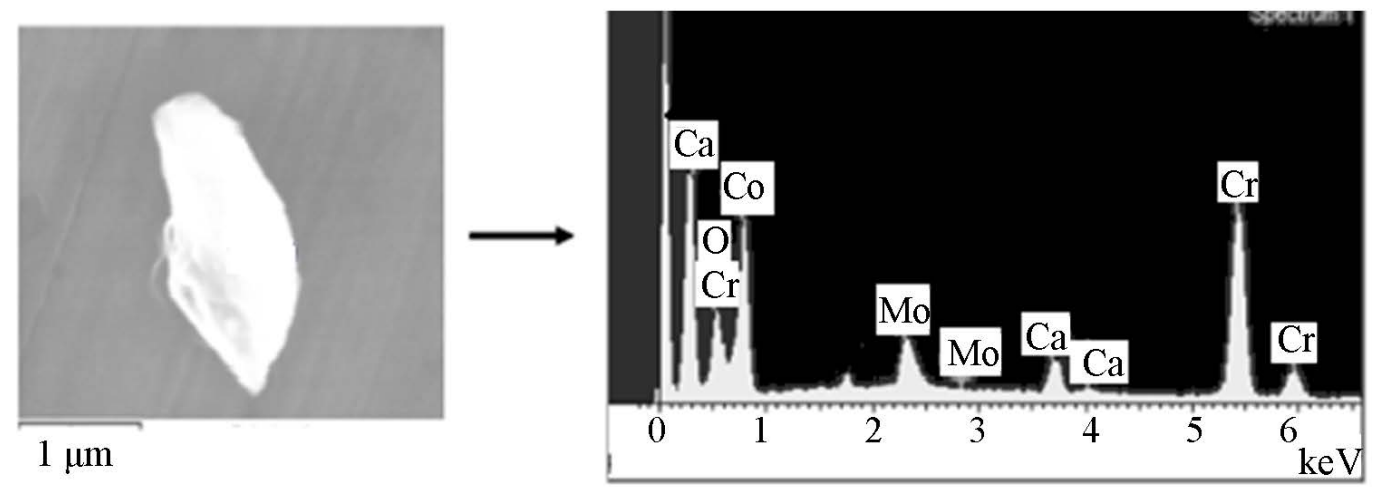

Figure 4. A collected particle from wear rate of $\mathrm{O}\left(400^{\circ} \mathrm{C}\right)$.

Table 1. Wear rate after oxygen treatment of $\mathrm{CoCr}$ alloy in relation to untreated sample.

\begin{tabular}{ccc}
\hline Samples & Friction coefficient & Wear rate $\left(\mathbf{1 0}^{-\mathbf{1 4}} \mathbf{~ m}^{\mathbf{3}} \mathbf{N m}\right)$ \\
\hline Reference & $0.26 \pm 0.01$ & $7.20 \pm 0.80$ \\
$\mathbf{O}\left(\mathbf{3 0 0}^{\circ} \mathbf{C}\right)$ & $0.25 \pm 0.01$ & $7.70 \pm 0.20$ \\
$\mathbf{O}\left(\mathbf{3 5 0}^{\circ} \mathbf{C}\right)$ & $0.25 \pm 0.01$ & $7.60 \pm 0.30$ \\
$\mathbf{O}\left(\mathbf{4 0 0}^{\circ} \mathbf{C}\right)$ & $0.26 \pm 0.01$ & $6.00 \pm 0.20$ \\
\hline
\end{tabular}


After removing particles with a size lower that $220 \mathrm{~nm}$, the total quantity of the different released ions (Co, $\mathrm{Cr}$ and Mo) was also reduced. In this case, from the total released ions of the untreated samples, the treated samples reduced their released ions around 15\% (Figure 6). Here, the highest reduced released ion was found to be $\mathrm{Cr}$ ion.

Taking into account experimental results it could established that around $10 \%$ of ion release is induced from particles in the medium. As different reductions are found for $\mathrm{Co}$ and $\mathrm{Cr}$ concentrations, at least two different kinds of particles must be present. $\mathrm{Cr}_{2} \mathrm{O}_{3}$ containing particles from the oxide layer comprise one class while particles originating from the base material are also present. The former group should be biomedically inert as $\mathrm{Cr}(\mathrm{III})$ is known for rapid formation of insoluble precipitates with a possible grain size of much less than 220 $\mathrm{nm}$. At the same time, relative toxicities of ions and nanoparticles have to be compared with literature data pointing towards more negative effects for particles than ions [29].

\subsection{XRD Analysis}

Figure 7 shows differences in the XRD analysis of the treated samples and untreated samples. New peaks in the outer surface of the oxygen treated samples are observed. These peaks indicate $\mathrm{Cr}_{2} \mathrm{O}_{3}$ forming a passive layer in the surface of the F-799 CoCr alloy. These peaks became smaller and showed a higher intensity with increasing processing temperature, indicating larger crystallites at higher temperatures. Moreover, some weak molybdenum oxides might be observed.

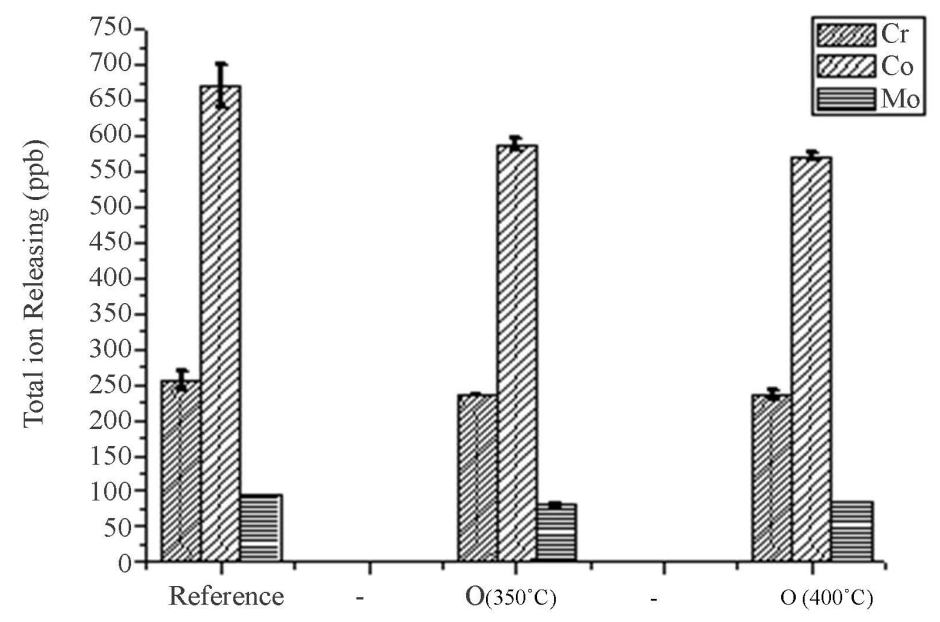

Figure 5. Comparison of the total released ions obtained by ICP-MS analyses of the unfiltered BSA samples.

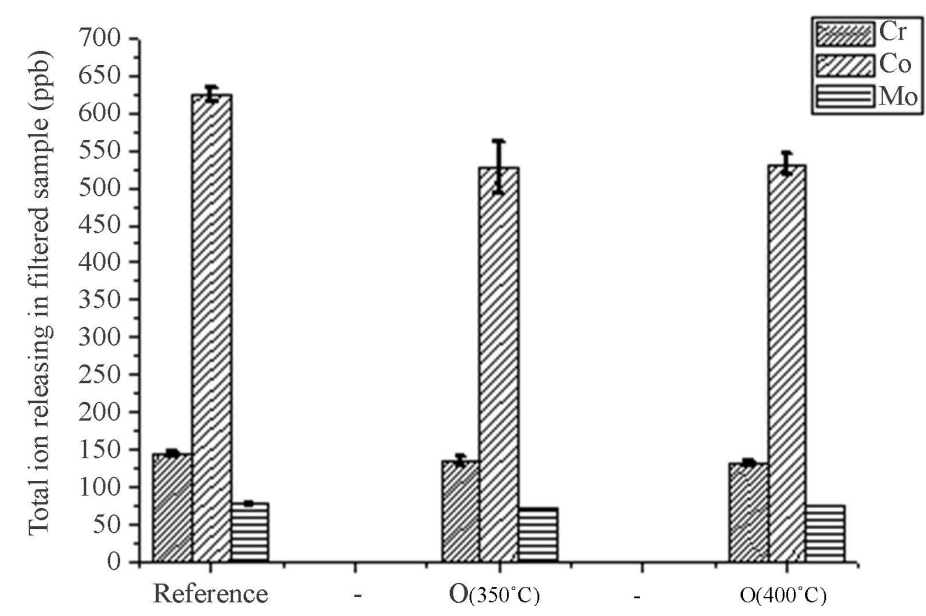

Figure 6. Total released ions after filtering of the BSA from wear tests. 


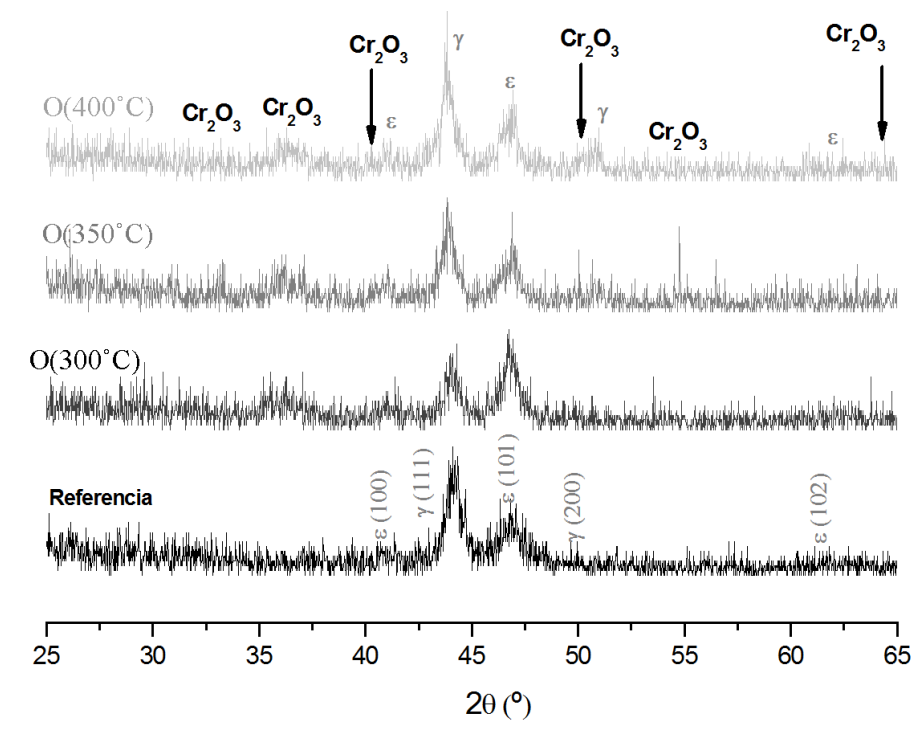

Figure 7. Comparison of XRD analysis of treated samples in relation to untreated samples.

\section{Summary \& Conclusion}

A F-799 CoCr alloy was treated by oxygen PI3 in order to simultaneously improve wear rate and corrosion resistance and as a consequence, ion release rates. The results of this work show a surface modification of about 30 - $40 \mathrm{~nm}$ of the structure of CoCr alloy and creation of some superficial oxide [30]. This process introduces an excellent corrosion resistance, similar to TiAlV keeping on similar wear rate factor to the untreated CoCr alloy. As a consequence, a reduction around $10 \%-20 \%$ of released ions was obtained from these tests using BSA. The average of released Co ions have been reduced while the quantity of $\mathrm{Cr}$ and Mo ions are very similar than in $\mathrm{CoCr}$ without treating. It could be explain due to $\mathrm{Cr}$ and $\mathrm{Mo}$ ions are forming oxides after the treatment with oxygen, and only Co ions would remain loose. It might introduce a higher probability in Co releasing than the rest of ions [31].

Additional studies characterising the collected wear particles are planned for the future [32]. At the moment after analysing surface of them, some oxides are covering them keeping an inert surface apparently [33].

The processing temperature itself was not a significant parameter for the determination of the results. The effectiveness of even higher temperatures has to be investigated while metallurgical transformations of the biomaterial F-799 during processing have to be avoided.

Moreover, further superficial treatments studies are carrying out in order to attempt to obtain a high reduction in released ions [34].

\section{Acknowledgements}

The authors would like to thank to the Ministry of Science and Innovación \& Navarra Government for FUNCOAT project and to the Ministry of Economy and Competitiveness for MoM for LIFE (MAT2011-29698C03-02) and for providing financial support to these projects”.

\section{References}

[1] Holzwarth, U. and Cotogno, G. (2012) JRC Scientific and Policy Reports. Publications Office of the European Union, European Commission, Luxembourg.

[2] OECD (2011) Health at a Glance 2011. Report, OECD Publishing.

[3] Burns, A.W. and Bourne, R.B. (2006) Economics of Revision Total Hip Arthroplasty. Current Orthopaedics, 20, 203207. http://dx.doi.org/10.1016/j.cuor.2006.02.007

[4] Tennent, T.D. and Goddard, N.J. (2000) Current Attitudes to Total Hip Replacement in the Younger Patient: Results of a National Survey. Annals of The Royal College of Surgeons of England, 82, 33-38. 
https://www.researchgate.net/publication/12614461

[5] Karas, S. (2012) Outcomes of Birmingham Hip Resurfacing: A Systematic Review. Asian Journal of Sports Medicine, 3, 1-7.

[6] Davis, J.R. (2003) Handbook of Materials for Medical Devices. ASM International.

[7] Yan, Y., Neville, A., Dowson, D., Williams, S. and Fisher, J. (2008) Tribo-Corrosion Analysis of Wear and Metal Ion Release Interactions from Metal-on-Metal and Ceramic-on-Metal Contacts for the Application in Artificial Hip Prostheses. Proceedings of the Institution of Mechanical Engineers Part J-Journal of Engineering Tribology, 222, 483-492. http://dx.doi.org/10.1243/13506501JET366

[8] Cawley, J., Metcalf, J.E.P., Jones, A.H., Bandb, T.J. and Skupien, D.S. (2003) A Tribological Study of Cobalt Chromium Molybdenum Alloys Used in Metal-on-Metal Resurfacing Hip Arthroplasty. Wear, 255, 999-1006. http://dx.doi.org/10.1016/S0043-1648(03)00046-2

[9] McMinn, D., Daniel, J., Ziaee, H. and Pradhan, C. (2011) Indications and Results of Hip Resurfacing. International Orthopaedics, 35, 231-237. http://dx.doi.org/10.1007/s00264-010-1148-8

[10] Tipper, J., Ingham, E., Jin, Z. and Fisher, J. (2005) The Science of Metal-on-Metal Articulation. Current Orthopaedics, 19, 280-287. http://dx.doi.org/10.1016/j.cuor.2005.08.002

[11] Hart, A.J., Sabah, S.A., Bandi, A.S., Maggiore, P., Tarassoli, P., Sampson, B. and Skinner, J.A. (2011) Sensitivity and Specificity of Blood Cobalt and Chromium Metal Ions for Predicting Failure of Metal-on-Metal Hip Replacement. The Journal of Bone \& Joint Surgery (British Volume), 93, 1308-1313. http://dx.doi.org/10.1302/0301-620X.93B10.26249

[12] Barry, M. (2010) New York Times.

[13] De Smet, K., De Haan, R., Calistri, A., Campbell, P.A., Ebramzadeh, E., Pattyn, C. and Gill, H.S. (2008) Metal Ion Measurement as a Diagnostic Tool to Identify Problems with Metal-on-Metal Hip Resurfacing. Journal of Bone \& Joint Surgery (American Volume), 90, 202-208. http://dx.doi.org/10.2106/JBJS.H.00672

[14] Peters, K., Schmidt, H., Unger, R.E., Kamp, G., Pröls, F., Berger, B.J. and Kirkpatrick, C.J. (2005) Paradoxical Effects of Hypoxia-Mimicking Divalent Cobalt Ions in Human Endothelial Cells in Vitro. Molecular and Cellular Biochemistry, 270, 157-166.

[15] Patntirapong, S., Habibovic, P. and Hauschka, P.V. (2009) Effects of Soluble Cobalt and Cobalt Incorporated into Calcium Phosphate Layers on Osteoclast Differentiation and Activation. Biomaterials, 30, 548-555. http://dx.doi.org/10.1016/j.biomaterials.2008.09.062

[16] Wedemeyer, C., Xu, J., Neuerburg, C., Landgraeber, S., Malayar, N.M., von Knoch, F., Gosheger, G., von Knoch, M., Loer, F. and Saxler, G. (2007) Particle-Induced Osteolysis in Three-Dimensional Micro-Computed Tomography. Calcified Tissue International, 81, 394-402. http://dx.doi.org/10.1007/s00223-007-9077-2

[17] Merkel, K.D., Erdmann, J.M., McHugh, K.P., Abu-Amer, Y., Ross, F.P. and Teitelbaum, S.L. (1999) Tumor Necrosis Factor Alpha Mediates Implant Osteolysis. American Journal of Pathology, 154, 203-210. http://dx.doi.org/10.1016/S0002-9440(10)65266-2

[18] Gallo, J., Raska, M., Mrazek, F. and Petrek, M. (2008) Bone Remodeling, Particle Disease and Individual Susceptibility to Periprosthetic Osteolysis. Physiological Research, 57, 339-349.

[19] Sabokbar, A., Pandey, R., Quinn, J.M. and Athanasou, N.A. (1998) Osteoclastic Differentiation by Mononuclear Phagocytes Containing Biomaterial Particles. Archives of Orthopaedic and Trauma Surgery, 117, 136-140. http://dx.doi.org/10.1007/s004020050213

[20] Wolner, C., Nauer, G.E., Trummer, J., Putz, V. and Tschegg, S. (2006) Possible Reasons for the Unexpected Bad Biocompatibility of Metal-on-Metal Hip Implants. Materials Science and Engineering: C, 26, 34-40. http://dx.doi.org/10.1016/j.msec.2005.05.004

[21] Pereira, M.C., Pereira, M.L. and Sousa, J.P. (1999) Histological Effects of Iron Accumulation on Mice Liver and Spleen after Administration of a Metallic Solution. Biomaterials, 20, 2193-2198. http://dx.doi.org/10.1016/S0142-9612(99)00124-6

[22] Oberdörster, G., Oberdörster, E. and Oberdörster, J. (2005) Nanotoxicology: An Emerging Discipline Evolving from Studies of Ultrafine Particles. Environmental Health Perspectives, 113, 823-839. http://dx.doi.org/10.1289/ehp.7339

[23] Kim, K.J., Kobayashi, Y. and Itoh, T. (1998) Osteolysis Model with Continuous Infusion of Polyethylene Particles. Clinical Orthopaedics and Related Research, 352, 46-52. http://dx.doi.org/10.1097/00003086-199807000-00007

[24] Mediero, A., Frenkel, S.R., Wilder, T., He, W., Mazumder, A. and Cronstein, B.N. (2012) Adenosine $A_{2 A}$ Receptor Activation Prevents Wear Particle-Induced Osteolysis. Science Translational Medicine, 4, 168-177. http://dx.doi.org/10.1126/scitranslmed.3003393

[25] Liu, X., Chu, P.K. and Ding, C. (2004) Surface Modification of Biomaterials Using Plasma Immersion Ion Implantation and Deposition. Materials Science and Engineering: R, 47, 49-121. http://dx.doi.org/10.1016/j.mser.2004.11.001 
[26] Tian, X., Gong, C., Yang, S., Luo, Z., Fu, R.K.Y. and Chu, P.K. (2006) Oxygen Plasma Ion Implantation of Biomedical Titanium Alloy. IEEE Transactions on Plasma Science, 34, 1235-1240. http://dx.doi.org/10.1109/TPS.2006.879002

[27] Mändl, S. (2009) Increased Biocompatibility and Bioactivity after Energetic PVD Surface Treatments. Materials, 2, 1341-1387. http://dx.doi.org/10.3390/ma2031341

[28] Manova, D., Mändl, S. and Rauschenbach, B. (2001) Heat Balance during Plasma Immersion Ion Implantation. Plasma Sources Science and Technology, 10, 423-429.

[29] Ponti, J., Sabbioni, E., Munaro, B., Broggi, F., Marmorato, P., Franchini, F., Colognato, R. and Rossi, F. (2009) Genotoxicity and Morphological Transformation Induced by Cobalt Nanoparticles and Cobalt Chloride: An in Vitro Study in Balt/3T3 Mouse Fibroblasts. Mutagenesis, 24, 439-445.

[30] Catelas, I., Bobyn, J.D., Medley, J.B., Krygier, J.J., Zukor, D.J. and Huk, O.L. (2003) Size, Shape, and Composition of Wear Particles from Metal-Metal Hip Simulator Testing: Effects of Alloy and Number of Loading Cycles. Journal of Biomedical Materials Research, 67A, 312-327. http://dx.doi.org/10.1002/jbm.a.10088

[31] Korovessis, P., Petsinis, G., Repanti, M. and Repantis, T. (2006) Metallosis after Contemporary Metal-on-Metal Total Hip Arthroplasty. Journal of Bone \& Joint Surgery (American Volume), 88, 1183-1191.

[32] Díaz, C., Lutz, J., Mändl, S., García, J.A., Martínez, R., Rodríguez, R.J., Damborenea, J.J., Arenas, M.A. and Conde, A. (2008) Comparison of Tribological Behaviour and Biocompatibility of Ti6Al4V Alloy after Ion Implantation or Thermal Oxidation. Physica Status Solidi (C), 5, 947-951. http://dx.doi.org/10.1002/pssc.200778310

[33] Díaz, C., García, J.A., Mändl, S. and Rodríguez, R.J. (2011) Plasma Immersion Ion Implantation for the Prevention of Metal Ion Release from CoCrMo Alloys. IEEE Issue-Applications and Numerical Simulation of Plasma Surface Modification, 39, 3045-3048.

[34] Kostov, K.G., Ueda, M., Lepienskyc, M., Soares, P.C., Gomes, G.F., Silva, M.M. and Reuther, H. (2004) Surface Modification of Metal Alloys by Plasma Immersion Ion Implantation and Subsequent Plasma Nitriding. Surface \& Coatings Technology, 186, 204-208. http://dx.doi.org/10.1016/j.surfcoat.2004.04.027 